\title{
Feminismo em foco: uma leitura crítica sobre a antologia Traduçôes da cultura*
}

Fabiana Gomes de Assis**

O livro que será apresentado nas páginas seguintes é, antes de tudo, um abraço. Falo nesses termos porque, enquanto mulher e pesquisadora feminista, vejo reverberar, nesse monumental trabalho, um rompimento de fronteiras que me impedem de olhar unicamente através da lente acadêmica, pois ele também toca no ponto de minha própria experiência. É nesse sentido que o pessoal e o político convergem para se tornarem faces de um mesmo evento, permitindo-me dizer às mulheres que se fazem críticas das desigualdades sociais, assim como eu, que é sempre e cada vez mais necessário que leiamos sobre nós mesmas, que sejamos todas ouvidos e olhos e bocas em coletividade.

É por isso que brindo ao lançamento da antologia Traduçôes da cultura: perspectivas críticas feministas (1970-2010) (2017). Nesse abraço de mais de 800 páginas, reflete-se o trabalho coletivo de sete anos de grandes mulheres pesquisadoras dos vários cantos do Brasil. A partir do extenso e colaborativo processo de seleção, em que foram traduzidos para o português 21 ensaios - originalmente publicados em inglês, francês e espanhol, a maioria em traduções inéditas para o português -, evidencia-se o cuidado e a abrangência desse projeto que, além do trabalho de tradução, comporta um lado crítico em forma de comentário com as vozes de muitas pesquisadoras nacionais e internacionais. Tudo

\footnotetext{
* Recebida em 20 de novembro de 2017, aceita em 17 de janeiro de 2019. Resenha de: BRANDÃo, Izabel et alii (org.) Traduções da cultura: perspectivas críticas feministas (1970-2010). Florianópolis, EDUFAL, Editora da UFSC, 2017.

** Doutora em Estudos Literários pelo Programa de Pós-Graduação em Letras e Linguística da Universidade Federal de Alagoas, Maceió, AL, Brasil. deassis.fabianagomes@gmail.com / https://orcid.org/0000-0002-3377-6804
} 
isso se faz presente desde a capa. A tradução gráfica da tela No jardim elétrico da artista plástica alagoana Marta Emília, que compõe sua exposição Acrilírika (2015), ilustra coerentemente a relação simbiótica entre natureza $e$ artifício, tema bastante teorizado no contexto do pensamento feminista. Aliás, a proposta interdisciplinar que comunica arte e cultura não é pura casualidade, se considerarmos o fato de que suas organizadoras estão imersas nos terrenos dos Estudos literários e linguísticos, tecendo conexões teórico-críticas com as mais variadas esferas do conhecimento, dentre as quais, os muitos feminismos, os Estudos de gênero, os Estudos pós- e de- coloniais, os Estudos queer, entre outras variações.

Por meio da tradução enquanto processo de deslocamentos e cruzamentos de diversas culturas, a antologia surge também para suprir uma lacuna epistemológica do contexto crítico brasileiro no que concerne aos textos feministas mais clássicos, assim como, em perspectiva diacrônica, permitir-nos visualizar melhor os percursos e desfechos, sempre provisórios, das discussões em torno da "classe social, geração, raça/etnia $e$ sexualidade, bem como questões da ecologia e das mobilidades dos sujeitos", conforme descrevem as organizadoras na apresentação do volume (Brandão et alii, 2007:17).

Neste momento de truculenta renovação fundamentalista pelo qual tem passado a cultura e a política brasileiras, a publicação dessa coletânea soa como uma das faces de uma contranarrativa de resistência povoada por membras/os da sociedade acadêmica interessadas/os na construção de um sentimento de não mais temer as ontologias pretensamente inquestionáveis. Sob a organização das Profas. Dras. Ana Cecília A. Lima, Claudia de Lima Costa, Ildney Cavalcanti e Izabel Brandão, o trabalho coletivo de mapeamento, seleção e tradução, que constitui a antologia Traduçôes da cultura, torna-se marco para a abertura de portas a outros projetos que visem à democratização do conhecimento, do ponto de vista dos feminismos, dos Estudos de gênero e queer, e à criação de espaços de trânsito e coalizão em escala transnacional. 
Se, por um lado, a organização dos textos segue a uma coerência cronológica que perpassa as décadas de 70, 80, 90 e 10, por outro, ela não se reduz a uma linearidade no âmbito da crítica, pois cada um dos ensaios se entrecruza em diversas nuances epistemológicas. Talvez não seja ao acaso que o primeiro deles, a encenar as rotas de entrada dos anos de 1970, "Quando da morte acordamos: a escrita como re-visão", de Adrienne Rich, traga à tona a necessidade de retorno crítico ao passado como forma de reescrever a história numa perspectiva anti-opressora. Em menor ou maior escala, esse é o fio condutor que une as diversas partes dessa antologia: o exercício contínuo de re-visão da história, entendida como "o ato de olhar para trás, de ver com um novo olhar, de entrar em um texto a partir de uma nova direção crítica" (2017:66). Esse ato, além de político, implica também um ato de sobrevivência do ponto de vista da experiência das mulheres, ainda que, no panorama histórico atual, possamos estender essa ideia à reflexão da categoria do humano, por compreender que a re-visão das bases fundadoras dessa instância ontológica deve contribuir para um avanço ético no modo como pensamos acerca de nós mesmas/os e nas relações intersubjetivas e interespécies que nos atravessam.

A divisão da antologia em blocos que abarcam décadas serve ao público brasileiro, de modo mais geral, como um guia de leitura crítico, pois viabiliza a compreensão da trajetória do pensamento feminista, desde os interstícios setentistas, quando a preocupação estava mais voltada à tomada de voz das mulheres $e$ ao questionamento da estrutura social hierárquica, até os desdobramentos interdisciplinares posteriores. O primeiro impulso tomado pela crítica foi, assim, buscar outros caminhos para entender as disparidades entre homens $e$ mulheres $e$, consequentemente, denunciar a origem dessas diferenças como forma de atenuá-las. Nesse contexto, a re-visão histórica ganhou contornos diversos mesmo tendo se projetado mais fortemente com a polêmica dialética entre natureza e cultura, como é expresso por Sherry B. Ortner em um dos textos que integram a coletânea, "Está a mulher para o homem assim como a natureza 
para a cultura?", publicado pela primeira vez em 1972. Ele reverbera um sentimento bastante comum a várias feministas da época que, assim como Ortner, desafiaram a presumida situação de "desvalorização universal das mulheres" e engajaram-se na luta por direitos básicos, seja no âmbito ativista ou acadêmico. A reinvindicação de que as mulheres não deveriam mais serem reduzidas às funções bio e fisiológicas do corpo, cujo efeito era a submissão doméstica e política, marcou esse período. Desse modo, passou a não ser mais aceita por um grupo de pensadoras $e$ ativistas a ideia de que a inferiorização da mulher no âmbito familiar e sua exclusão do setor público acontecia em decorrência de uma propensão natural do corpo e da psique que se traduzia numa deficiência cultural. Em outras palavras, aspectos naturalmente irrefutáveis atrelados ao corpo das mulheres, como a menstruação e a maternidade, por exemplo, eram sustentados para reforçar o esquema patriarcal que, com a mesma intensidade, atribuía aos homens a função social de sujeito público dotado de capacidade intelectual diferenciada e racional por natureza. É sobre essa realidade hierarquizada que Ortner questiona de forma arguta e conclui:

Logo, é claro que a situação deve ser discutida de ambos os lados; os esforços dirigidos unicamente à mudança das instituições sociais, por exemplo, por meio do estabelecimento de quotas salariais ou por meio da aprovação das leis de igualdade de trabalho e salário não podem ter efeitos de longo alcance se a linguagem $e$ as figuras culturais continuam a fornecer uma imagem relativamente desvalorizada da mulher (Ortner, 2017:122).

Note-se que a autora coloca a possibilidade de mudança social como condição e consequência de uma transformação que deve ocorrer primeiramente no contexto da linguagem. Vai se tornando cada vez mais evidente que o sistema de representação vigente, ao operar nos domínios do discurso, é o principal elemento de uma economia patriarcal que oprime as mulheres, definindo-as como não sujeitos e localizando-as rigidamente fora 
dos limites da linguagem e, assim, fora também da história. Nesse sentido, para que a realidade social fosse modificada, era necessário que houvesse o que Hélène Cixous definiu, em célebre ensaio intitulado "O riso da medusa", como uma "tomada da palavra" (Cixous, 2017:136). Para ela, ainda que a história da escrita esteja muito próxima à história da razão, fato que nos permite constatar a equivalência entre a exclusão presumida das mulheres e a colonização falocêntrica do pensamento, é na escritura que reside a "própria possibilidade da mudança" (grifos da autora, p. 134). Publicado pela primeira vez em 1975, o tom exclamativo que perpassa todo o ensaio, aproximando-o, em certa medida, de características presentes em manifestos, exprime os caminhos que seguiu o ativismo e a crítica feminista da época, sempre em luta contra o silenciamento da mulher. A partir das teorizações de Rich, Ortner e Cixous, que integram, juntamente com Laura Mulvey, Sandra Gilbert \& Susan Gubar, a primeira parte da antologia Traduçóes da cultura, somos capazes de reconhecer os impactos iniciais do pensamento feminista norteamericano e europeu, assim como restabelecer um pouco da atmosfera que serviu de base para as muitas ramificações da crítica que ocorreram mais fortemente em meados da década de 90 em decorrência das questões referentes à interseccionalidade.

A parte da antologia que compreende os anos de 1980 está concentrada, assim, na época em que o processo de re-visão se estendeu às práticas feministas e possibilitou uma crescente interdisciplinaridade com áreas como a antropologia, a psicanálise e a filosofia, o que contribuiu para fortalecer esse campo de estudos em perspectiva cultural, política e subjetiva. Seguindo a lógica corrente de que a superação das desigualdades entre mulheres e homens deveria acontecer primeiramente por meio da linguagem, em uma enfática "transformação política dos conceitos-chave" (Wittig, 2017:271), como reforça Monique Wittig no ensaio "O pensamento straight', originalmente publicado em 1978, a necessidade de extrapolar os limites impostos por uma estrutura de saber construída pela concepção de sujeitos invariáveis e ditada pela heterossexualidade normativa levou 
algumas feministas à consideração das questões concernentes aos movimentos de liberação gay e lésbica.

A tomada de voz, antes pensada sob o guarda-chuva da homogeneizada categoria "mulher" passou a fazer parte de uma ação mais ampla que atingiu outros grupos sociais desprivilegiados, incitando reflexões que desmistificassem a ideia de coerência identitária tão presente em cada uma dessas instâncias.

Além disso, ao longo da década de 80 , a preocupação com a complexidade histórico-cultural das diferenças se mostrou um passo inevitável da crítica, pois uma prática feminista que não levasse em conta outros marcadores sociais, como a classe $e$ a etnia, por exemplo, os contextos sócio-culturais específicos e, além disso, o desejo enquanto elemento fugidio e não presumidamente heterocêntrico, corria o risco de reproduzir a mesma lógica binária opressora a qual propunha subverter. Chandra Talpade Mohanty, em "Sob os olhos do ocidente: estudos feministas e discursos coloniais" (1988), outro texto que integra em versão traduzida a antologia, tangencia essas questões quando discute sobre as relações entre a autorrepresentação discursiva das feministas ocidentais e a representação das mulheres do terceiro mundo.

A autora aponta para o cuidado ético em se evitar metodologias de análise que, ao conceberem as mulheres como um grupo homogêneo, sustentam certa "unidade a-histórica" (2017:330) que restringe suas experiências, ao mesmo tempo em que pressupõe uma relação hierárquica entre mulheres estabelecida pela dialética do sujeito e do objeto, na qual as mulheres do "terceiro mundo" são geralmente vistas como o outro da cultura, em comparação as dos países mais desenvolvidos economicamente. É preciso reiterar que a linearidade cronológica encenada pelos textos não pressupõe uma compartimentalização no campo do conhecimento, apenas ilustra de forma diacrônica $e$ metodológica os passos do pensamento feminista, de modo mais amplo, e suas intersecções.

Os ensaios que estão presentes na terceira parte, cujo subtítulo é "do gênero às suas intersecções", correspondem ao 
recorte temporal da década de 90. Dentro desse espaço, observase que os rumos da (auto)crítica são cada vez mais favoráveis a uma verticalização feminista, no sentido de promover uma amplificação das outras vozes silenciadas, assim como considerar a complexa e nem sempre coerente formação das subjetividades. A rotulação identitária é tomada sob rasura $e$ isso se deve à insuficiência ética de uma crítica que nega a polifonia humana, como se pode depreender do emblemático texto de Gloria Anzaldúa, "Queer(izar) a escritora - Loca, escritora y chicana", publicado originalmente em 1991. Refletindo acerca do seu lugar de fala, Anzaldúa revela os paradoxos do ato de nomear quando ele serve à reiterada exclusão das pessoas advindas de contextos culturais não centralizados. A autora aponta para o uso do termo "lésbica", comumente relacionado às mulheres brancas e de classe média e, assim, por vezes não aplicável a mulheres que, como ela, auto-rotulada "chicana mestiza de classe operária", trazem experiências culturais que excedem os critérios embutidos nessa nomenclatura, assim como em tantas outras. No entanto, Anzaldúa não nega por completo o rótulo. Aliás, expõe a força contida no ato metafórico de plantarmos os pés no chão $e$ falarmos do lugar de nossas próprias vivências, enquanto leitoras/es do mundo que nos cerca, sem que isso signifique um solapamento das partes que nos constituem por formas que homogeneízem negativamente nossas diferenças. Além disso, a postura de alerta compartilhada por muitas escritoras nos anos de 1990, como é o caso de bell hooks (1992) e Gayatri Spivak (1999), também incluídas na coletânea Traduções da cultura, é um meio útil para a construção de metodologias de análise mais justas histórica e culturalmente.

Susan Stanford Friedman explicita bem essas questões quando traz à tona em seu ensaio "Além" do gênero: a nova geografia da identidade e o futuro da crítica feminista", publicado primeiramente em 1996, os aspectos possíveis das novas geografias da crítica que ela classificou como "feminismo localista" (2017:523), no qual a identidade é compreendida como múltipla, contraditória, relacional, situacional e híbrida, afastando-se, com 
isso, das abordagens da ginocrítica e da ginesia das décadas de 70 e 80 que tomavam o gênero como "pressuposto apriorístico" (2017:556) na formação de identidades estáveis. Os anos de 1990 foram, assim, férteis na elaboração interdisciplinar das novas vertentes feministas que se desenvolveram com mais impacto no atual milênio, em que figuram alguns trabalhos pontuais de nomes como Donna Haraway (2003), Judith Butler (2004) e Greta Gaard (2010). É indispensável mencionar que essas pensadoras produzem desde meados da década de 70 , no caso de Haraway, $e$ de 90 , em se tratando de Butler e Gaard. A inserção dessas escritoras na última parte da antologia "Anos 2000: novas topografias teórico-críticas" parece uma necessidade especificamente metodológica de situar melhor, no contexto histórico da seção, as temáticas mais discutidas.

O questionamento da primazia do gênero na constituição do pensamento feminista, possibilitado desde $90 \mathrm{com}$ os Estudos queer, suscitou mais recentemente uma crítica profunda do humano em sua presumida autoevidência $e$ a relação que estabelece com o entorno. O pós-humanismo, a ecocrítica e o que vem sendo classificado como "antropoceno" ganham cada vez mais espaço enquanto dispositivos de reconfiguração social poderosos do ponto de vista histórico-cultural, político, epistemológico e acadêmico - que nos permitem pensar e, quem sabe, materializar sociedades mais justas. Nesse sentido, a organização de Traduçóes da cultura e a recepção por parte do público leitor brasileiro do amplo corpus de ensaios feministas mais clássicos que comportam a antologia certamente irá acrescentar em muito ao cenário da crítica "local", contribuindo para investigações acadêmicas no campo das humanidades, e, como efeito, ajudando a fortalecer nossa luta diária contra a grande onda de fundamentalismos que assolam o país.

\section{Referência bibliográfica}

ANZALDÚA, Glória. Queer(izar) a escritora - Loca, escritora y chicana. Tradução de tatiana nascimento. In: BRANDÃO, Izabel (org.) 
Traduções da cultura: perspectivas críticas feministas (1970-2010). Florianópolis, EDUFAL, Editora da UFSC, 2017.

BRANDÃO, Izabel (org.) Traduções da cultura: perspectivas críticas feministas (1970-2010). Florianópolis, EDUFAL, Editora da UFSC, 2017.

CIXOUS, Hélène. O riso da medusa. Tradução de Luciana Eleonora de Freitas Calado Deplagne. In: BRANDÃO, Izabel (org.) Traduções da cultura: perspectivas críticas feministas (1970-2010). Florianópolis, EDUFAL, Editora da UFSC, 2017.

FRIEDMAN, Susan Standford. "Além" do gênero: a nova geografia da identidade e o futuro da crítica feminista. Tradução de Alcione Cunha da Silveira \& Sandra Regina Goulart Almeida. In: BRANDÃO, Izabel (org.) Traduções da cultura: perspectivas críticas feministas (19702010). Florianópolis, EDUFAL, Editora da UFSC, 2017.

MOHANTY, Chandra Talpade. Sob os olhos do ocidente: estudos feministas e discursos coloniais. Tradução de Maria Isabel de Castro Lima. In: BRANDÃO, Izabel (org.) Traduçóes da cultura: perspectivas críticas feministas (1970-2010). Florianópolis, EDUFAL, Editora da UFSC, 2017.

ORTNER, Sherry B.. Está a mulher para o homem assim como a natureza para a cultura?. Tradução de Cila Ankier e Rachel Gorenstein. In: BRANDÃO, Izabel (org.) Traduçôes da cultura: perspectivas críticas feministas (1970-2010). Florianópolis, EDUFAL, Editora da UFSC, 2017.

$\mathrm{RICH}$, Adrienne. Quando da morte acordamos: a escrita como re-visão. Tradução de Susana Bornéo Funck. In: BRANDÃO, Izabel (org.) Traduções da cultura: perspectivas críticas feministas (1970-2010). Florianópolis, EDUFAL, Editora da UFSC, 2017.

WITTIG, Monique. O pensamento straight. Tradução de Ana Cecília Acioli Lima. In: BRANDÃO, Izabel (org.) Traduções da cultura: perspectivas críticas feministas (1970-2010). Florianópolis, EDUFAL, Editora da UFSC, 2017. 